\title{
STRUCTURAL PATTERN ANALYSIS
}




\section{World Scientific Series in Computer Science}

\section{Published}

1: Computer-Aided Specification Techniques (J Demetrovics, E Knuth \& P Rado)

2: Proceedings of the 2nd RIKEN International Symposium on Symbolic and Algebraic Computation by Computers (Eds. $N$ Inada \& $T$ Soma)

3: Computational Studies of the Most Frequent Chinese Words and Sounds (Ching Y Suen)

4. Understanding and Learning Statistics by Computer ( $M C K$ Yang \& $D H$ Robinson)

5: Visualizing Abstract Objects and Relations - A Constraint-Based Approach (T Kamada)

6: DC Flux Parametron - A New Approach to Josephson Junction Logic (E Goto \& K F Loe)

8: Information, Randomness \& Incompleteness - Papers on Algorithmic Information Theory ( $G J$ Chaitin)

9: P-Prolog - A Parallel Logic Programming Language (Rong Yang)

10: Intelligent Chinese Language Pattern and Speech Processing (Ed. P S-P Wang)

11: Control Theory of Robotic Systems (J M Skowronski)

12: An Introduction to Chinese, Japanese, and Korean Computing ( $K T$ Huang \& T D Huang)

13: Mathematical Logic for Computer Science $(Z W L u)$

14: Computer Vision and Shape Recognition (Eds. A Krzyzak, T Kasvand \& C Y Suen)

15: Stochastic Complexity in Statistical Inquiry (J Rissanen)

16: A Perspective in Theoretical Computer Science - Commemorative Volume for Gift Siromoney (Ed. $R$ Narasimhan)

17: Computer Transformation of Digital Images and Patterns ( $Z C L i, T D B u i, Y Y$ Tang \& C Y Suen)

18: Array Grammars, Patterns and Recognizers (Ed. $P$ S $P$ Wang)

19: Structural Pattern Analysis (Eds. R Mohr, Th Pavlidis \& A Sanfeliu)

\section{Forthcoming}

7: Syntactic and Structural Pattern Recognition - Theory and Applications (Eds. H Bunke \& A Sanfeliu)

20: A Computational Model of First Language Acquisition (N Satake)

21: The Design and Implementation of ConcurrentSmalltalk (Y Yokote) 
Series in Computer Science - Vol. 19

\title{
STRUCTURAL
}

\section{PATTERN \\ ANALYSIS}

A selection of papers presented at the workshop organized by the IAPR Technical Committee on Syntactical and Structural Pattern Recognition

(Pont-à-Mousson, 1988)

\author{
Editors \\ Roger Mohr \\ LIFIA-IMAG, Grenoble \\ Theo Pavlidis \\ SUNY, Stonybrook \\ Alberto Sanfeliu \\ Universitat Politècnica, Barcelona
}

\section{World Scientific}




\section{Published by}

World Scientific Publishing Co. Pte. Ltd., P O Box 128, Farrer Road, Singapore 9128

USA office: 687 Hartwell Street, Teaneck, NJ 07666

UK office: 73 Lynton Mead, Totteridge, London N20 8DH

\section{Library of Congress Cataloging-in-Publication Data}

Structural pattern analysis/editors, Roger Mohr, Theo Pavlidis, Alberto Sanfeliu.

p. cm. -- (Series in computer science; vol. 19)

"A selection of papers presented at the workshop organized by the IAPR Technical Committee on Syntactical and Structural Pattern Recognition (Pont-à-Mousson, 1988)" ISBN 9810200978

1. Pattern recognition systems -- Congresses. I. Mohr, Roger. II. Pavlidis, Theodosios. III. Sanfeliu, Alberto. IV. IAPR Technical Committee on Syntactical and Structural Pattern Recognition. V. Series. TK7882.P3S77 1989 620'.00285'642 -- dc20

\section{STRUCTURAL PATTERN ANALYSIS}

Copyright @ 1990 by World Scientific Publishing Co. Pte. Ltd.

All rights reserved. This book, or parts thereof, may not be reproduced in any form or by any means, electronic or mechanical, including photocopying, recording or any information storage and retrieval system now known or to be invented, without written permission from the Publisher.

ISBN 981-02-0097-8

Printed in Singapore by JBW Printers \& Binders Pte. Ltd. 


\section{PREFACE}

The IAPR Technical Committee on Syntactical and Structural Pattern Recognition organises regular workshops on its themes. In 1989, the workshop was held in Pont-à-Mousson, France, with the collaboration of CRIN (Computer Research Institute of Nancy) and INRIA Lorraine. This volume contains a selection of papers presented at this workshop; the papers have been extended in order to provide a maximum amount of information to the reader. Fundamental aspects of pattern recognition and syntactical analysis of shapes are explored, as well as applications in this area. Among these applications, document processing is a particular domain, represented by four papers.

Bringing together people from academic and industrial research centers leads to many fruitful exchanges. We therefore decided to include, at the end of this volume, the reports from three working groups. They provide a summarizing view of the numerous discussions held during the workshop.

We would like to thank here the program committee members who carried out their task with admirable dedication. We also thank NATO, Région Lorraine and the city of Nancy for their financial support, and CRIN and INRIA Lorraine for their support in organising the workshop.

R. Mohr

Th. Pavlidis

A. Sanfeliu 
This page is intentionally left blank 


\section{CONTENTS}

Preface

\section{Papers}

Parsing Multivalued Strings and Its Application to Image and Waveform Recognition

H. Bunke \& D. Pasche

Inductive Learning of Finite-State Transducers for the Interpretation of Unidimensional Objects

E. Vidal, P. García \& E. Segarra

On the Use of an Ear Model and Multi-Layered Networks for Automatic Speech Recognition

R. De Mari, Y. Bengio \& R. Cosi

The Pattern Complex

R. M. Haralick

Matching Complex Structures: The Cyclic-Tree Representation

Scheme

A. Sanfeliu

A Knowledge Based Industrial Vision System

S. Schröder, H. Niemann, G. Sagerer, H. Brünig \& R. Salzbrunn

Hierarchical Cooperation Between Numerical and Symbolic Image Representations

G. Paar \& W. G. Kropatsch

3-D Object Recognition Based on Subgraph Matching in

Polynomial Time

E. Gmür \& H. Bunke

Feature Grouping: A Way to Deterministic Matching

R. Mohr, L. Quan \& E. Thirion 
Use of Shadows for Extracting Buildings in Aerial Images

Y. -T. Liow \& Th. Pavlidis

Global-to-Local Layout Analysis

H. S. Baird

A Syntactic Approach to Document Segmentation

M. Viswanathan \& M. S. Krishnamoorthy

An Entity Extractor for Images of Engineering Drawings

S. H. Joseph

Analysis of Technical Documents Using a priori Knowledge

K. Tombre \& D. Antoine

\section{Reports of Working Groups}

Working Group: Hybrid Methods

Report of Working Group on Document Analysis and Line-Graphics Processing 